\title{
Penerapan PSAK 109 Pelaporan Keuangan Akuntansi Zakat dan Infaq/Shadaqah pada LAZISMU
}

\author{
Andreani Hanjani*, Kholifah Nur Azizah, Barbara Gunawan \\ D3 Akuntansi, Universitas Muhammadiyah Yogyakarta, Indonesia
}

This study aims to investigate how the application of PSAK 109 contained in LAZISMU and to evaluate the suitability of financial statements contained in LAZISMU with PSAK 109. The research method used is descriptive qualitative with interview, documentation and observation techniques. This research was conducted at the Amil Zakat Infaq Alms Muhammadiyah Institute in Yogyakarta. The results of this study indicate that LAZISMU mostly still uses the application of PSAK 45, which is about the financial reporting of nonprofit entities where the benefits are not obtained through business but rather derived from social and humanitarian. In presenting LAZISMU's financial statements it only applies a summary of the program, which is to record each zakat and infaq / alms fund and the percentage of funds distributed to each asnaf this is contrary to the application of PSAK 109, wherein recording financial statements consists of statements of financial position, reports of changes in funds, reports of changes in funds, reports changes in assets under management, statements of cash flows and notes to financial statements. These results can be concluded that the recording of financial statements at LAZISMU is not fully in accordance with PSAK 109.

\section{Keywords: IAZIZMU, financial report, PSAK 109}

OPEN ACCESS

ISSN 2548-3501 (online)

Edited by:

Eny Maryanti

Reviewed by:

Rina Trisnawati

*Correspondence:

Andreani Hanjani

andreani@umy.ac.id

Received: 29 Maret 2019

Accepted: 20 April 2019

Published: 31 Juli 2019

Citation:

AH, KNA and BG (2019) Penerapan PSAK 109 Pelaporan Keuangan

Akuntansi Zakat dan

Infaq/Shadaqah pada LAZISMU.

Journal of Accounting Science. 3:2.

doi: 10.21070/jas.v3i2.2468
Penelitian ini bertujuan untuk menginvestigasi bagaimana penerapan PSAK 109 yang terdapat di LAZISMU serta untuk mengevaluasi kesesuaian laporan keuangan yang terdapat di LAZISMU dengan PSAK 109. Metode penelitian yang digunakan adalah deskriptif kualitatif dengan teknik wawancara, dokumentasi dan observasi. Penelitian ini dilaksanakan di Lembaga Amil Zakat Infaq Sedekah Muhammadiyah Yogyakarta. Hasil penelitian ini menunjukkan bahwa LAZISMU sebagian besar masih menggunakan penerapan PSAK 45 yaitu mengenai pelaporan keuangan entitas nirlaba dimana keuntungannya tidak diperoleh melalui bisnis melainkan diperoleh dari sosial dan kemanusiaan. Dalam penyajian laporan keuangan LAZISMU hanya menerapkan iktisar program yaitu untuk pencatatan setiap dana zakat dan infaq/sedekah serta jumlah presentase yang disalurkan ke setiap asnaf hal ini bertentangan dengan penerapan PSAK 109 dimana dalam pencatatan laporan keuangan terdiri atas laporan posisi keuangan, laporan perubahan dana, laporan perubahan aset kelolaan, laporan arus kas dan catatan atas laporan keuangan. Hasil tersebut dapat disimpulkan bahwa pencatatan laporan keuangan di LAZISMU belum sepenuhnya sesuai dengan PSAK 109.

Keywords: LAZIZMU, laporan keuangan, PSAK 109 


\section{PENDAHULUAN}

Persoalan kemiskinan yang terjadi di negara berkembang salah satunya di Indonesia merupakan fenomena global. Pemerintah saat ini terus meningkatkan kesejahteraan masyarakat miskin Indonesia khususnya dalam bidang ekonomi. Hal ini dapat dilihat dari upaya pemerintah menerapkan dua sistem perekonomian yang dikenal dunia yaitu, sistem ekonomi kapitalisme dan sistem ekonomi sosialisme. Kedua upaya pemerintah belum dapat menawarkan solusi yang optimal hingga sekarang. Oleh karena itu, alternatif yang diyakini dapat lebih menjanjikan adalah sistem ekonomi islam dimana sistem ini berpijak pada asas keadilan dan kemanusiaan. Untuk mengaplikasikan kepedulian sosial dan meningkatkan kesejahteraan umat manusia, islam memberikan sebuah media yang biasa dikenal dengan sebutan zakat. Untuk merealisasikan kepedulian sosialnya islam mengharuskan umatnya yang sudah memenuhi syarat untuk berzakat. Zakat merupakan salah satu dari lima rukun Islam yang salah satu kewajiban mendasar dalam Islam (Abdullah (2014)

Menurut Wulansari (2014) tujuan zakat tidak hanya sekedar menyantuni orang miskin secara konsumtif, tetapi juga untuk mengurangi kemiskinan dan mengangkat derajat fakir miskin dengan membantu keluar dari kesulitan hidup. Zakat merupakan ibadah maliyah dimana mempunyai dimensi dan fungsi sosial ekonomi serta merupakan solidaritas sosial, pernyataan rasa kemanusiaan dan keadilan, pembuktian persaudaraan islam, pengikut persatuan umat dan bangsa, sebagai penghilang jurang yang menjadi pemisah antara golongan kaya dengan golongan miskin.

Dalam hal ini pengelolaan zakat memerlukan sistem akuntasi yang baik dan ketertiban dalam administrasi keuangan serta sistem informasi manajemen memadai agar zakat benar-benar bisa dikelola dengan baik dan benar untuk disalurkan dengan tepat kepada mustahiq. Sumber daya manusia yang memiliki keahlian dalam bidang manajerial, pengetahuan agama serta keterampilan teknis diperlukan bagi pengelola zakat yang profesional. Permasalahan mendasar yang sering dihadapi pengelola zakat adalah standarisasi dalam sistem akuntansi dan audit laporan keuangan. Hal tersebut dikarenakan ketidakfahaman pengurus zakat atau amil sehingga masih banyak BAZ dan LAZ yang belum dapat menerapkan pelaporan keuangannya sesuai dengan PSAK 109 tentang akuntansi zakat, infaq/shadaqah terutama badan amil zakat yang beroperasi dalam lingkup desa/kelurahan atau masjid, yang mana mereka masih menggunakan konvensional.

Sistem manajemen akuntansi dan keuangan yang baik menjadi salah satu faktor yang akan meningkatkan kepercayaan masyarakat. Sistem akuntansi yang jelas sumber dan penggunaan dana zakat diharapkan pengelolaan zakat menjadi lebih efektif, efisien dan lebih transparan serta akuntabel (Rahman (2015) . Organisasi pengelola zakat harus memiliki pedoman pengelola zakat, yaitu Undang-undang No. 23 tahun 2011 dan Peraturan Pemerintah Nomor 14 Tahun 2014 mengenai pengelolaan zakat yang dikeluarkan pemerintah. Sejalan dengan hal tersebut IAI telah mengesahkan standar yang mengatur pengelolaan dana zakat yaitu PSAK 109 tentang akuntansi zakat dan infaq/shadaqah yang disusun dengan tujuan untuk mengatur pengakuan, pengukuran, penyajian, dan pengungkapan transaksi zakat, infaq, dan shadaqah. Pernyataan Standar Akuntansi Keuangan 109 ini dapat mengakomodir masukan dari berbagai lembaga zakat yang mempunyai perlakuan akuntansi yang berbeda untuk satu jenis transaksi yang sama. Terbentuknya PSAK 109 masalah perbedaan perlakuan akuntansi di lembaga zakat dapat diminimalisir perbandingannya secara umum.

Penelitian mengenai penerapan PSAK No.109 Pelaporan Keuangan Akuntansi Zakat, Infaq/Shadaqah diantaranya dilakukan oleh Indrawati (2016) dalam penelitiannya menunjukkan bahwa BAZNAS Provinsi Jatim belum sempurna menerapkan pasal 29 namun telah melaksanakan pengelolaan dana ZIS sesuai UU No. 23 tahun 2011 pasal 21 hingga pasal 28 dan pasal 31. BAZNAS Provinsi Jatim juga telah melakukan sesuai PP No. 14 tahun 2014 pasal 71 hingga pasal 76 sebagai pendukung pasal 29 UU No. 23 tahun 2011, akan tetapi pada pasal 71 dan 75 belum sempurna dilaksanakan. Hal tersebut terlihat bahwa BAZNAS Provinsi Jatim belum menyampaikan laporan pertanggungjawaban secara berkala tiap 6 bulan dan akhir tahun serta belum dilakukan audit atas laporan keuangan oleh akuntan publik. Selain itu, beberapa kebijakan akuntansi BAZNAS Provinsi Jatim sesuai dengan PSAK 109 meskipun masih ada beberapa yang belum sesuai baik dari segi pengakuan dan pengukuran serta penyajian dan pengungkapan. Hal ini dikarenakan adanya ketidakefektifan pengelolaan keuangan yang ada dalam BAZNAS Provinsi Jatim serta keterbatasan SDM akuntansinya. Hidayat et al. (2018) menemukan bahwa laporan keuangan Yayasan Rumah Yatim Arrohman sesuai dengan Pernyataan Standar Akuntansi Keuangan (PSAK) No. 109. Faktor pendukung dari implementasi PSAK 109 yang sudah sesuai ini diantaranya ialah manajemen organisasi pengelola zakat yang profesional dan adanya bantuan dari software khusus untuk pelaporan keuangan. Penelitian lain yang dilakukan oleh Ritonga (2017) menunjukkan bahwa Laporan keuangan yang disajikan oleh BAZNAS Sumatera Utara masih belum informatif, hal ini disebabkan karena perlakuan akuntansi zakat belum sepenuhnya sesuai PSAK NO. 109.

Melihat masih banyaknya organisasi pengelola zakat yang belum menerapkan akuntansi zakat dan infaq/shadaqah serta sedikitnya referensi riset yang membahas pelaporan keuangan akuntansi zakat dan infaq/shadaqah sedangkan isu topik ini hangat untuk dapat diteliti, maka membuat peneliti tertarik mengenai penerapan pelaporan zakat dan infaq/shadaqah di LAZISMU. Penelitian ini bertujuan mengetahui kesesuaian penerapan akuntansi mengenai pengakuan, pengukuran, penyajian dan pengungkapan laporan keuangan Zakat dan Infaq/Shadaqah dengan PSAK No. 109. Secara teoritis, penelitian ini bertujuan untuk menambah wawasan mengenai keuangan syariah khususnya mengenai pelaporan keuangan akuntansi zakat dan infaq/shadaqah.Selain itu, secara praktis penelitian ini memberikan kontribusi bagi pihak lembaga 
keuangan syariah sebagai bahan evaluasi penerapan praktik syariah yang efektif dan sesuai dengan PSAK No. 109.

\section{METODE PENELITIAN}

Penelitian ini merupakan penelitian kualitatif dengan pendekatan studi kasus yang dilakukan untuk memberikan kesimpulan mengenai penerapan PSAK no 109 atas Pelaporan Keuangan Akuntansi Zakat dan Infaq pada LAZISMU. Objek dari penelitian ini adalah LAZISMU yang beralamat di Jl. Gedong Kuning 130 B Yogyakarta 5571. Dalam penelitian ini, peneliti mendeskripsikan penerapan akuntansi zakat dan infak/shadaqah pada LAZISMU. Data yang telah dikumpulkan dianalisis dengan membandingkan akuntansi zakat dan infak /shadaqah yang diterapkan pada LAZISMU dengan PSAK 109. Penelitian ini menggunakan jenis data primer dan sekunder. Data primer yaitu hasil wawancara yang diperoleh dari pengelola ZIS di LAZISMU dan hasil dokumentasi. Sedangkan data skunder yang digunakan dalam penelitian ini berupa, laporan neraca, laporan laba rugi.

\section{HASIL DAN PEMBAHASAN}

\section{Pengakuan zakat dan infaq/shadaqah}

LAZISMU menerima zakat dalam bentuk kas dan diakui sebagai penambah dana zakat disetiap adanya kas yang masuk dan juga sebaliknya dana yang keluar diakui sebagai pengurang dana zakat. LAZISMU juga menerima infaq/sedekah dalam bentuk kas. Infaq/shadaqah yang diterima diakui sebagai dana amil untuk bagian amil dan dana infaq/shadaqah untuk bagian penerima infaq/shadaqah yang mana besaran presentasinya ditentukan amil sesuai dengan prinsip syariah. Penyaluran jumlah dana infaq/shadaqah ditentukan sendiri dari pihak LAZISMU dan dalam penyalurannya harus habis atau sesuai dengan jumlah yang telah ditentukan.

\section{Penyajian zakat dan infaq/shadaqah}

Pengakuan dana non halal di LAZISMU memisahkan antara dana zakat, dana infaq/sedekah dan dana amil didalam buku rekening. Jadi setiap dana masing-masing memiliki satu rekening.

\section{Pengungkapan Zakat Infaq Sedekah}

Dalam pengungkapan dilaporan keuangan LAZISMU menentukan jumlah dan presentase untuk masing-masing mustahiqyangtelah sesuai dengan syariah yaitu presentase zakat sebesar $12,5 \%$ dan untuk infaq telah ditentukan oleh lembaga. LAZISMU juga mengungkapkan kebijakan penyaluran zakat, seperti penentuan skala prioritas dan penerima zakat. Laporan keuangan LAZISMU mengungkapakan kebijakan pembagian antara dana amil dan dana non amilatas penerima zakat, seperti presentase pembagi (dana amil di zakat $12,5 \%$ dan dana infaq 20\%), alasan dan konsistensi kebijakan. Rincian jumlah penyaluran dana diungkapakan berupa berapa penghimpunan, berapa pentasyarufannya dan sesuai jumlah mustahiqnya. Dalam hal ini LAZSIMU menggunkan double rekening yaitu penghimpunan dan pentasyarufan untuk mengetahui jumlah dana yang terkumpul dan yang disalurkan.

\section{Pengukuran zakat dan infaq/sedekah}

Jika terjadi penurunan nilai aset maka LAZISMU melakukan banyak penghimpunan dana dengan begitu semakin banyak pula dana yang dapat ditasyarufkan. Maka dalam kasus ini dapat dikatakan LAZISMU merupakan lembaga yang menerapkan PSAK 45 atau nirlaba dimana keuntungannya tidak melalui bisnis tetapi melalui sosial dan kemanusiaan.

Berdasarkan hasil evaluasi dari laporan keuangan LAZISMU dapat disimpulkan sebagai berikut:

[Table 1 about here.]

Berdasarkan Tabel 1 laporan keuangan yang diterapkan oleh LAZISMU belum sepenuhnya sesuai dengan PSAK 109 dimana LAZISMU hanya menerapkan dua komponen yang terdapat di PSAK 109 yaitu pengakuan, dan pengungkapan, dimana LAZISMU sebagian masih mengacu pada PSAK 45 tentang pelaporan keuangan entitas nirlaba. Didalam komponen pengukuran LAZSIMU belum merealisasikannya, jadi jika terjadi penurunan nilai aset amilakan mencari banyak penghimpunan dana sedangkan dalam PSAK 109 dijelaskan dalam laporan perubahan dana, jika terjadi penurunan aset maka kerugian ditanggung sesuai dengan penyebab terjadinya kerugian tersebut. Dalam penyajian laporan keuangan, LAZISMU hanya membuat laporan keuangan berupa ikhtisar program sedang dalam PSAK 109 terdapat laporan posisi keuangan untuk penyajian dana zakat, dana infaq, dan dana shadaqah yang dicatat secara terpisah. Laporan ikhtisar program LAZISMU hanya menyajikan setiap penencatatan dana yang disalurkan serta jumlah penerima dana tersebut, didalam laporan keuangan ini LAZSIMU juga mencatat setiap jumlah dana serta jumlah presentase yang akan disalurkan kepada setiap asnaf atau penerima zakat dan infaq/sedekah, sedangkan jika dalam penerapan PSAK 109 setiap jumlah dana disajikan dalam laporan perubahan dana dan untuk setiap presentase maupun setiap kegiatan akuntansi yang tidak dicatat dimanapun disajikan dalam catatan atas laporan keuangan.

\section{KESIMPULAN}

Penyajian laporan keuangan LAZISMU hanya membuat laporan keuangan berupa ikhtisar program yang didalamnya telah mencantumkan setiap transaksi maupun setiap kegiatan yang berkaitan dengan akuntansi zakat dan infaq/shadaqah.Dalam penerapannya terhadap PSAK 109 LAZISMU hanya menganut pada 2 komponen saja yaitu pengakuan dan pengungkapan. Pada penyajian zakat dan infaq/shadaqah LAZISMU menyajikan dana zakat, dana infaq/shadaqah, dan dana amil secara terpisah dalam rekening. Bank Syariah Bukopin digunakan sebagai rekening yang menyimpan dana zakat dan Bank Mandiri Syariah merupakan rekening yang menyimpan dana 
infaq/shadaqah. LAZISMU sebagian masih mengacu pada penerapan PSAK 45 yaitu tentang pelaporan keuangan entitas nirlaba dimana keuntungannya tidak melalui bisnis laba rugi namun melalui sosial dan kemanusiaan.

\section{REFERENCES}

Abdullah, A. A. (2014). Factors Influencing a Business Towards Zakat Payment In Malaysia. Universiti Sultan Zainal Abidin. Malaysia. International journal of Science Commerce and Humanities. Jurnal 2.

Hidayat, S., Rohaeni, N., and , A. Z. (2018). Implementasi Pernyataan Standar AKuntansi Keuangan 109 pada Yayasan Rumah Yatim Arrohman. Jurnal Akuntansi Terapan Indonesia 1, 17-26.

Indrawati, R. (2016). Evaluasi Penerapan Undang-Undang Pengelolaan Zakat dan Akuntansi Zakat (PSAK 109) Pada BAZNAS Provinsi JATIM”. Jurnal Akuntansi UNESA 4.

Rahman, T. (2015). Akuntansi Zakat, Infak dan Sedekah (PSAK 109): Upaya Peningkatan Transparansi dan Akuntabilitas Organisasi Pengelola Zakat (OPZ). Jurnal Muqtasid 6, 141-164.

Ritonga, P. (2017). Analisis Akuntansi Zakat Berdasarkan PSAK No. 109 Pada Badan Amil Zakat Nasional. KITABAH: Jurnal Akuntansi dan Keuangan Syariah

\section{UCAPAN TERIMA KASIH}

Peneliti mengucapkan terima kasih kepada LAZISMU yang beralamat di Jl. Gedong Kuning 130 B Yogyakarta 5571, LP3M Universitas Muhammadiyah Yogyakara, Program Studi D3 Akuntansi Program Vokasi Universitas Muhammadiyah Yogyakarta serta pihak-pihak terkait yang selalu memberikan dukungan sehingga kami dapat menyelesaikan artikel ini.

$$
1,1-19 \text {. }
$$

Wulansari, S. D. (2014). Analisis Peranan Dana Zakat Produktif Terhadap perkembangan usaha mikro Mustahik (Penerima Zakat) Studi Kasus rumah zakat kota semarang. Diponegoro Journal of Economics 3.

Conflict of Interest Statement: The authors declare that the research was conducted in the absence of any commercial or financial relationships that could be construed as a potential conflict of interest.

Copyright (C) 2019, and. This is an open-access article distributed under the terms of the Creative Commons Attribution License (CC BY). The use, distribution or reproduction in other forums is permitted, provided the original author(s) and the copyright owner(s) are credited and that the original publication in this journal is cited, in accordance with accepted academic practice. No use, distribution or reproduction is permitted which does not comply with these terms. 


\section{LIST OF TABLES}

1 Evaluasi Penerapan PSAK 109 pada LAZISMU 
TABLE 1 | Evaluasi Penerapan PSAK 109 pada LAZISMU

\begin{tabular}{ll}
\hline No & Penerapan PSAK 109 \\
\hline 1. & Pengakuan zakat harus diakui pada saat kas atau aset lainnya diterima, \\
& zakat yang diterima diakui sebagai penambah zakat.Jika dalam ben- \\
& tuk kas maka sebesar jumlah yang diterima, jika dalam bentuk non kas \\
& maka sebesar nilai wajar aset non kas tersebut.
\end{tabular}
sesuai dengan jumlah yang telah

3. Pengakuan dana non halal, penerimaan non halal diakui sebagai dana non halah, yang terpisah dari dana zakat, dana infaq/shadaqah.

4.

Pengukuran zakat, jika terjadi penurunan nilai aset nonkas, jumlah kerugian yang ditanggung harus diperlakukan sebagai pengurang dana zakat atau pengurang dana amil tergantung dari sebab terjadinya kerugian.

5. Pengukuran infaq/shadaqah yang diterima dapat berupa kas atau aset nonkas. Aset non kas dapat berupa aset lancar atau aset tidak lancar.

6.

Penyajian ZIS, amil menyajikan dana zakat, dana infaq, dana shadaqah, dana amil, dan dana non halal secara terpisah dalam neraca.

7.

Pengungkapan Zakat, harus mengungkapkan hal-hal terkait dengan transaksi zakat, tetapi tidak terbatas pada:

a. Kebijakan penyaluran zakat

b. Kebijakan pembagian dana amil dan dana non amil atas penerimaan zakat

c. Metode penentuan nilai wajar yang digunakan,

d. Rincian jumlah penyaluran dana zakat.

e. Hubungan istimewa antara amil dan mustahiq.

Pengungkapan infaq dan shadaqah, amil harus mengungkapkan hal-hal terkait dengan transaksi infaq/shadaqah, tetapi tidak terbatas pada: a. Penentuan nilai wajar yang digunakan untuk penerimaan berupa aset non kas.

b. Kebijakan pembagian antara dana amil dan dana non amilatas penerimaan infaq/shadaqah.

c. Kebijakan penyaluran infaq/shadaqah.

d. Rincian dana infaq/shadaqah berdasarkan peruntukannya LAZISMU dengan PSAK 109 ialah
Perlakuan akuntansi pada LAZISMU

a. Untuk penerimaan dalam bentuk kas LAZISMU telah menerapkan PSAK 109, namun belum untuk penerimaan aset non kas karena selama ini belum ada realisasi penerimaan aset non kas.

b. LAZISMU juga mengakui penerimaan zakat sebagai penambah dana zakat.

c. Zakat yang disalurkan kepada mustahiq diakui sebagai pengurang dana zakat.

a. Untuk penerimaan dalam bentuk kas LAZISMU telah menerapkan PSAK 109, namun belum untuk penerimaan aset non kas karena selama ini belum ada realisasi penerimaan aset non kas.

b. Infaq/shadaqah yang diterima diakui sebagai dana amil untuk bagian amil dan dana infaq/shadaqah untuk bagian penerima infaq/shadaqah yang mana besaran presentasinya ditentukan amil sesuai dengan prinsip syariah.

c. Penyaluran jumlah dana infaq/shadaqah ditentukan sendiri dari pihak LAZISMU dan dalam penyalurannya harus habis atau ditentukan.

Keterangan

Belum sepenuhnya sesuai

Belum sepenuhnya sesuai

Dalam penerimaan dana non halal,

LAZISMU diakui sebagai dana non halal, yang terpisah dari dana zakat, dana infaq/shadaqah dan dana amil.

Hingga saat ini belum ada perlakuan mengenai pengukuran atas penurunan nilai aset zakat non kas, karena belum ada realitanya.

Hingga saat ini belum ada perlakuan akuntansi mengenai pengukuran atas penurunan nilai aset infaq/shaqah non kas, karena belum ada realitanya.

Lembaga Amil Zakat Infaq Shadaqah Muhammadiyah menyajikan dana zakat, dana infaq, dana shadaqah, dana amil dan dana non halal secara terpisah dalam rekening bank, dan LAZISMU hanya menyajikan laporan keuangan berupa ikhtisar program.

Dalam pengungkapan dilaporan keuangan, maka perbedaan pengungkapan laporan keuangan LAZISMU dengan PSAK 109 ialah dimana dalam laporan keuangan LAZISMU tidak diungkapkan penentuan nilai wajar yang digunakan dalam aset non kas, terkait hal ini LAZSIMU tidak merealisasikan aset non kas pada dana zakat maupun infaq/shadaqah.

Dalam pengungkapan dilaporan keuangan, maka perbedaan pengungkapan laporan keuangan dimana dalam laporan keuangan LAZISMU tidak diungkapkan penentuan nilai wajar yang digunakan dalam aset non kas, terkait hal ini LAZSIMU tidak merealisasikan aset non kas pada dana zakat maupun infaq/shadaqah.
Sesuai

Belum sesuai

Belum sesuai

Belum sesuai

Belum sepenuh nya sesuai

Belum sepenuh nya sesuai 